\title{
Science and elephant management decisions in South Africa
}

\author{
K.D. Young, R.J. Van Aarde* \\ Conservation Ecology Research Unit, Department of Zoology and Entomology, University of Pretoria, Pretoria 0002, South Africa
}

\section{A R T I C L E I N F O}

\section{Article history:}

Received 5 July 2010

Received in revised form 24 November 2010

Accepted 28 November 2010

Available online $\mathrm{xxxx}$

\section{Keywords:}

Conservation

Management decisions

Elephants

End-users

Evidence-based conservation

Science uptake

\begin{abstract}
A B S T R A C T
Most conservation practitioners rely on experience-based information for management decisions. In South Africa, government policy thus directs managers to base decisions for elephant management on the best available scientific information. The reliance of their management decisions on science, however, is unknown. We interviewed 30 managers from small to large protected areas in South Africa to evaluate whether science underpinned strategic and applied management decisions regarding elephants. We also evaluated their perspectives on limitations to, and opportunities for, greater reliance on science. Twentynine managers valued science as a platform for their decisions. However, most managers based decisions on experience-based information. Only $28 \%, 30 \%$ and $8 \%$ of managers respectively developed objectives, identified issues and selected management methods on science-based information. Furthermore, only $30 \%$ selected a desired number of elephants, and $5 \%$ selected a population control method, according to science-based information. The probability of managers basing decisions on science-based information differed with management area size, tenure, planning timeframes and manager experience. However, except for experience, these relationships were weak, and overall an implementation gap between science and elephant management existed. Limitations for science to inform decisions included lack of relevance and application of science findings to respective management areas, and scientists' attitudes and credibility. Opportunities included more site specific studies, better communication of, and easier access to scientific material. These opportunities could enable scientists to contribute more effectively to elephant management decisions and improve the reliance on science among the wider community of conservation practitioners in Africa.
\end{abstract}

() 2010 Elsevier Ltd. All rights reserved.

\section{Introduction}

Conservation managers often must select among competing options to improve conservation outcomes. Because these decisions can affect the resource being managed (Cook et al., 2010), decisions should ideally be based on effectiveness as demonstrated by scientific experiments or systematic reviews of evidence (Pullin et al., 2004). Decision-makers need to know what actions do and do not work, or how effective a given action has been in achieving objectives (Pullin et al., 2004). However, despite an increase in the number of science publications that include management recommendations (Ormerod et al., 2002; Knight, 2009), an implementation gap between science and management exists (Possingham, 2009). Conservation managers still primarily rely on experiencebased and traditional land management practices, rather than on rigorous evidence-based science, for most conservation actions (Pullin et al., 2004; Cook et al., 2010). Hence, end-users may have their own perspectives about the value of science, about how links

* Corresponding author. Address: University of Pretoria, Department of Zoology \& Entomology, Zoology Building, Room 3.22.5, 0002 Pretoria, South Africa. Tel.: +27 12420 2753, mobile: +27 82908 7313; fax: +27 124204523 .

E-mail address: rjvaarde@zoology.up.ac.za (R.J. Van Aarde). between themselves and scientists might be strengthened, and about how the uptake of science might be further advanced (Ormerod et al., 2002; see also Balmford and Cowling, 2006).

We explored these questions among managers of elephant populations in South Africa. These managers formed a distinct end-user group that provided an opportunity to evaluate whether science is informing decisions aimed at maintaining or reducing the perceived impact of elephants on biodiversity. This group comprises both publically and privately funded individuals that are directed by government policy to base their management decisions on the best available scientific information to (among other aspirations) ensure the long term survival of elephants where they occur, and to ensure that elephants do not disrupt the ecological integrity of the ecosystems in which they occur (DEAT, 2008). These outcomes are sought to conform with South Africa's international biodiversity obligations (DEAT, 2008).

Like most conservation practitioners (see Cook et al., 2010), elephant managers face a myriad of often competing ecological, economic and social considerations (Biggs et al., 2008). Elephants are desirable in many protected areas and private and communal lands in Africa due to their considerable economic, ecological, cultural and aesthetic value (see Blignaut et al., 2008). However, determining a desired number of elephants and a population 
structure is complex (van Aarde et al., 2006; van Aarde and Jackson, 2007; Guldemond and van Aarde, 2008). This is because the impact of elephants on other species may be desirable or undesirable given the environmental context within which these impacts are considered (see Guldemond and van Aarde, 2008 and references therein; Kerley et al., 2008). Furthermore, consistent with the Convention on Biodiversity's 2010 target to ensure that processes and patterns are maintained at the ecosystem level (see http://www.cbd.int/ecosystem/), current elephant management approaches advocate a move away from deterministic practitioner based "command and control" thinking of the past, to dynamic savanna management objectives within which elephants are an interactive component (van Aarde and Jackson, 2007; Ladle and Gillson, 2009). Hence, given the policy directive and uncertainty associated with the management of dynamic systems, and with elephants in particular, we expected that managers would rely on defendable scientifically derived information for elephant management decisions.

We asked what information sources managers used to: (i) develop site-specific management objectives for the maintenance of biodiversity in the presence of elephants in their management areas; (ii) identify issues associated with meeting such objectives; and (iii) select elephant management methods aimed at addressing identified issues and fulfilling such objectives. These planning questions allowed us to explore the level of reliance on different information sources for strategic (objectives and issues) and applied (methods) decisions. To give direct relevance to these, we also asked what information sources managers used to define a desired population size within their respective management areas, and to select population control methods, if any. We chose these questions because efforts to address the problem of local overabundance of elephants have typically focused on reducing elephant numbers to reduce apparent impact (see van Aarde et al., 2008). Setting a desired number may therefore represent a strategic planning decision. Similarly, selecting a population control method may represent a practical on-the-ground management decision. We also evaluated manager's perceptions of the value of science for their decision making requirements. We therefore asked what limits the use of science in management decisions, and what opportunities exist for improving reliance on science?

To our knowledge this represents the first study which evaluates a specific end-user group's reliance on science in decision making processes in Africa. Because our end-user group is explicitly directed by government policy to base their decisions on the best available scientific information and is accountable for the consequences of their decisions, the results of our study may also reflect the upper end of the range of reliance on science for decision making among the wider community of conservation management practitioners in Africa.

\section{Methods}

\subsection{Data collection}

We approached 34 managers of 40 management areas with elephants in South Africa. These management areas excluded zoos and small holdings within larger reserves where small groups $(<10)$ of elephants were kept for entertainment such as elephant back safaris. Managers were selected as those individuals within each management area with responsibility for setting management objectives, making on-the-ground elephant management decisions, and who had accountability for those decisions.

Our initial approach to managers comprised an e-mail message followed by phone call to invite them to participate in an interview. In the e-mail message we explained the study's aims and provided a summary of the type of questions to be asked and how answers would be collated and used. We provided further clarification when required. All managers were assured that their responses would be confidential and that no information about themselves or their management area would be included in any publications based on our survey.

Participants were interviewed at their place of work. Interviews were conducted during October and November 2008 and April 2009. Each interview lasted one to two hours and comprised three sections. The first section sought details about the management area (size, tenure, governance, planning timeframes, proximity to other reserves, fenced or unfenced, provision of supplementary water), about the managers qualifications (formal-academic qualifications, on the job training and no training) and experience (years), their management role, and the elephant population which they managed (size, population growth rate, constrained or freeranging, whether a desired number of elephants was identified and whether the population size was presently controlled or not).

The second section addressed the hierarchical planning decisions for the management area. For this section, the planning terms 'objectives', 'issues' and 'methods' were explained to managers in the context of our study (Table 1). Managers were then asked to describe in their own words what the objectives were for the maintenance of biodiversity in the presence of elephants for their management area. Managers where further asked to describe associated issues and methods employed to meet these objectives. Following their descriptions, managers were asked for the primary information source for objectives, issues and methods (Table 2). In this section they were also asked if they had set a desired number of elephants for their area and whether they were currently implementing any population control measures. For both of these questions managers were asked for the primary information source for any decisions. We classified information sources into categories as defined by Cook et al. (2010) (Table 2). Our first category which we called 'science-based information' was equivalent to Cook et al.'s (2010) evidence-based information, and included studies documented in peer-reviewed journals as well as those in unpublished reports. We assumed that our inclusive rather than exclusive description of science-based information acknowledged mediums other than peer reviewed literature for transfer of scientific information and thus enabled our study to evaluate the broadest extent of manager reliance on science as a platform for elephant management decisions. Our second category - 'intermediate-based information', included a mixture of data sources and planning documents which may synthesize the best research but can also be based on personal experience (see Pullin and Knight, 2005). Thus we also included expert advice provided within a scientific and/or

Table 1

Planning terms described to each manager at the beginning of interviews.

\begin{tabular}{|c|c|}
\hline Planning term & Meaning \\
\hline $\begin{array}{l}\text { Objectives for the management of } \\
\text { elephants to maintain biodiversity }\end{array}$ & $\begin{array}{l}\text { An outcome sought for the maintenance of biodiversity in the management area which explicitly accounts for the presence of } \\
\text { elephants. For example: "Maintenance of sand forest in the presence of elephants" }\end{array}$ \\
\hline Elephant management issues & $\begin{array}{l}\text { An identified aspect of elephant presence that requires management consideration, attention and intervention to meet the } \\
\text { objectives for the management area }\end{array}$ \\
\hline Elephant management methods & $\begin{array}{l}\text { A specific course of action to address the issues above. For example: "Translocation of elephants to a less populated part of the } \\
\text { management area" or "Maintenance of elephant densities at a specified level in areas of high botanical value" }\end{array}$ \\
\hline
\end{tabular}


Table 2

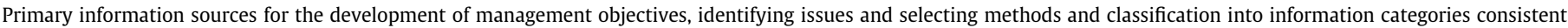
with Cook et al. (2010).

\begin{tabular}{|c|c|c|}
\hline Information source & Description & Information category \\
\hline Peer reviewed science findings & $\begin{array}{l}\text { Science findings detailed in a: } \\
\text { - A peer reviewed published scientific paper or book or book chapter. } \\
\text { - A conference presentation (oral or poster). } \\
\text { - A peer reviewed published scientific report. }\end{array}$ & Science-based information \\
\hline Scientific investigation & $\begin{array}{l}\text { An external or internal non-peer reviewed formal assessment undertaken by a } \\
\text { scientist or science student }\end{array}$ & Science-based information \\
\hline Management plans, wildlife sighting records & Knowledge derived from plans point data, ad hoc monitoring and/or mapping & Intermediate-based information \\
\hline Integrated Management Planning (IMP) & Agreed outcomes from a consultative process between experts and stakeholders & Intermediate-based information \\
\hline Expert advice & $\begin{array}{l}\text { Common knowledge and assumptions on elephant biology, elephant management } \\
\text { and the interaction between elephants and biodiversity held within collegial } \\
\text { networks, technical working groups, conservation practitioners, community } \\
\text { members or local specialists }\end{array}$ & $\begin{array}{l}\text { Intermediate-based information } \\
\text { source }\end{array}$ \\
\hline $\begin{array}{l}\text { Manager's field based observations and/or } \\
\text { experience }\end{array}$ & $\begin{array}{l}\text { Conclusions reached from the manager's observations on elephants and biodiversity. } \\
\text { This includes informed guesses made by managers while considering circumstantial } \\
\text { information and managers "gut feelings" }\end{array}$ & $\begin{array}{l}\text { Experience-based information } \\
\text { source }\end{array}$ \\
\hline Landowner(s) directive & $\begin{array}{l}\text { - Directive given by landowner(s). } \\
\text { - Agreement(s) between manager and landowner. } \\
\text { - Management area declaration documents. }\end{array}$ & $\begin{array}{l}\text { Experience-based information } \\
\text { source }\end{array}$ \\
\hline
\end{tabular}

consultative forum as intermediate-based information. Our third category- 'experience-based information', included manager experience, observation, personal opinion and landowner directives.

The third section sought the manager's perceptions of the value of conservation science for management decisions, and the limitations to and opportunities for, greater reliance on conservation science. Managers were asked to describe these perceptions in their own words and were able to identify more than one limitation and more than one opportunity.

\subsection{Data analysis}

We quantitatively reported managers' responses to Sections 1 and 2 of our interviews. For Section 2 we did this according to our information categories and we also used logistic regressions to determine whether the probability of a manager basing decisions (objectives, issues and desired number of elephants) on science-based information were functions of management area size, tenure, planning timeframe, years of manager experience and manager qualifications. We calculated separate regressions for each decision and only included managers who had made a decision. Note that we did not calculate regressions for decisions regarding the selection of methods or the selection of population control methods. This is because less than three managers based these decisions on science-based information. To overcome the presence of a few large values for management area size, planning timeframe and years of manager experience, we used the natural logs (ln) of these data. We used the F-test to test for significance of the regression. We also used the receiver operating characteristic curve value (ROC curve) to assess the overall accuracy of the model. The ROC curve value is calculated as the area under the curve of true positives versus false positives and therefore varies from 0.5 (discriminating power not better than chance) to 1.0 (perfect discriminating power). Accordingly it represents the percent of all possible pairs of cases in which the model assigns a higher probability to a correct case than to an incorrect case. Accuracy of the model thus increases with increasing ROC values once above 0.5 (Fielding and Bell, 1997).

We also evaluated the model stability (performance of the model to predict correct values from subsets of the data) using fivefold cross validation (cvROC) (see Bekkby et al., 2008).

For Section 3, we grouped limitations stated by managers into categories of similar nature and reported the number of managers stating a limitation in each. We conducted the same grouping exercise for manager stated opportunities.

\section{Results}

\subsection{The sample}

Thirty managers participated in our study (one per management area). One was the sole owner of the area which he managed, and another was one of several owners. All other managers reported to an executive committee or board of trustees. All managers interviewed were male. Their experience in elephant management ranged from 1 to 37 years with an average of 12.5 years and a median of 11 years. Twenty-one managers had formal qualifications in wildlife management, nature conservation, ecology or veterinary studies. Six had received on the job training, while three had no formal training or qualifications.

\subsection{The management areas}

Tenure: Five management areas were national parks, six were communally owned reserves and the remaining 19 were privately owned, either by a landowner's consortium or by one family. Nineteen managers made decisions independently from all other managers. The remaining 11 managers made decisions collectively with others, or sought the approval of others.

Management actions: 23 management areas were completely fenced and the remaining seven were partially fenced, thus providing elephants opportunities to move to other management areas. In 25 management areas supplementary water was provided. Twenty-six management areas were adjacent to other reserves with elephants.

Elephant populations: Elephants were translocated to 22 of the management areas to establish populations. A further management area received translocations to supplement an existing natural population. Almost all translocations were undertaken from mid 1992 to 1999 . Of the remaining seven management areas, three were original populations and four received elephants which colonized newly available areas through the removal of fences. The number of elephants, as given by managers, ranged from 10 to 14,500. The average was 1238 and the median was 98 .

Size: Management areas ranged from 5000 to $1,899,200$ ha. The average size was 110,745 ha and median size was 30,000 ha.

Planning timeframe: Management planning ranged from purely reactionary ( 0 years) to long term ( 70 years). The average planning period was 10 years and median was 5 years.

Only 25 management areas had objectives which had explicit outcomes for elephant management incorporated into those for 
biodiversity. However, all 30 management areas identified issues regarding the presence of elephants and the maintenance of biodiversity. Twenty-five management areas employed methods to minimize the impacts of elephants on biodiversity.

\subsection{Information sources for decisions}

\subsubsection{Broad management planning}

Objectives: 25 managers set objectives which explicitly sought biodiversity outcomes from elephant management. Among these managers a wide variety of information sources formed the basis of their decision making (Fig. 1). Seven of 25 managers who had set an objective relied on science-based information sources.

Issues: All 30 managers identified issues associated with the management of elephants to meet stated objectives (Fig. 1), even though not all managers had identified an objective. Most managers, $70 \%$ ( 21 of 30 ), identified issues from experience-based information sources. The other nine managers identified issues according to science-based information sources, these including scientific reports and peer reviewed published science findings.

Methods: 25 managers were currently implementing methods to manage elephants and maintain biodiversity. Almost all of these

(a) Objectives

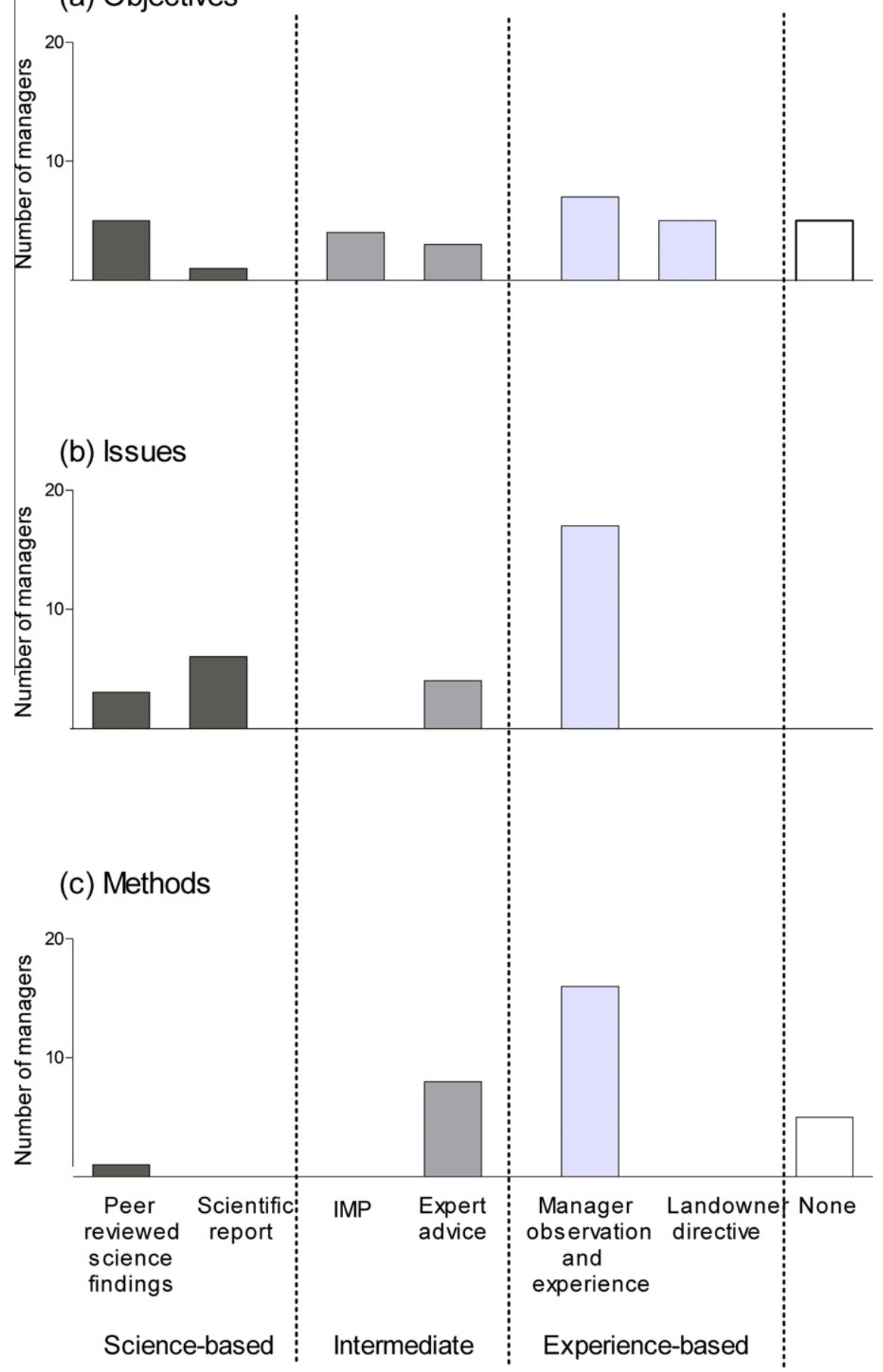

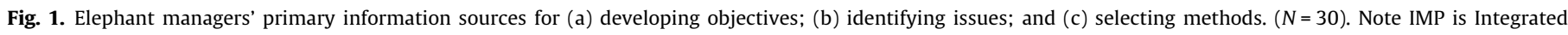
Management Planning. 
managers (23 of 25 ) selected methods according to experiencebased information sources, while only two selected methods according to science-based information sources (Fig. 1).

\subsubsection{Specific management decisions}

Desired number of elephants: 19 managers had identified a desired number of elephants for their management area while seven determined that the setting of a desired number was unnecessary. The remaining four managers did not identify a desired number (Fig. 2). Fourteen of the 26 managers who had made a decision based their decision on experience-based information (Fig. 2). Of note is that although three of these 14 managers had a number recommended to them by a site-based scientific report, they had chosen to rely on their own interpretation. Eight managers had adopted recommended numbers based on science-based information sources including site-specific scientific reports. The remaining four managers relied on intermediate information sources including management plans (Fig. 2).

Population control: 14 managers were currently implementing population control methods and five sought to implement control methods within 3 years (Fig. 2). Thus 19 had selected a population control method. Only one manager based his method of population control on science-based information. Ten of the 19 based their method on intermediate sources of information including site specific population counts and observations of population structure, while the remaining eight selected their methods according to experience-based information sources such as informal discussions with experts (Fig. 2). Control methods included contraception, translocation, hunting and destruction (Fig. 3).

\subsubsection{Explanatory factors}

Objectives: Management area size, tenure and planning timeframe significantly but weakly $\left(D^{2}=0.32,0.26\right.$ and 0.37 respectively) predicted the probability of a manager basing his objectives on science-based information (Table 3). ROC values for

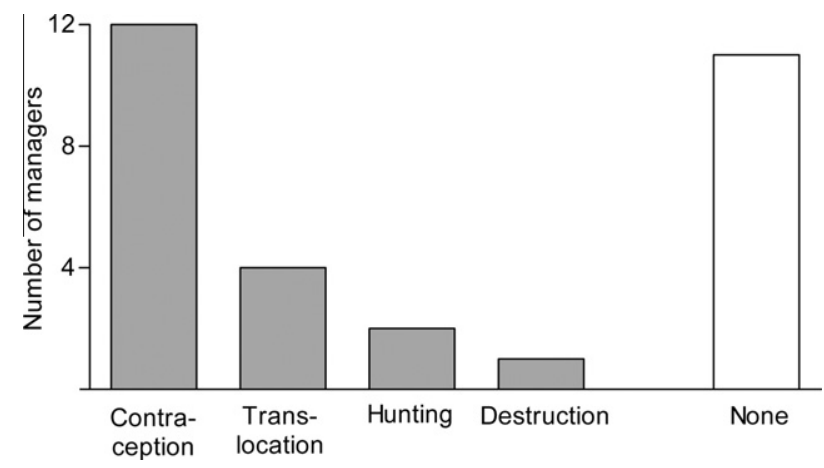

Fig. 3. Population control methods currently employed, or to be employed within 12 months by 30 elephant managers.

\section{(a) Desired number of elephants}

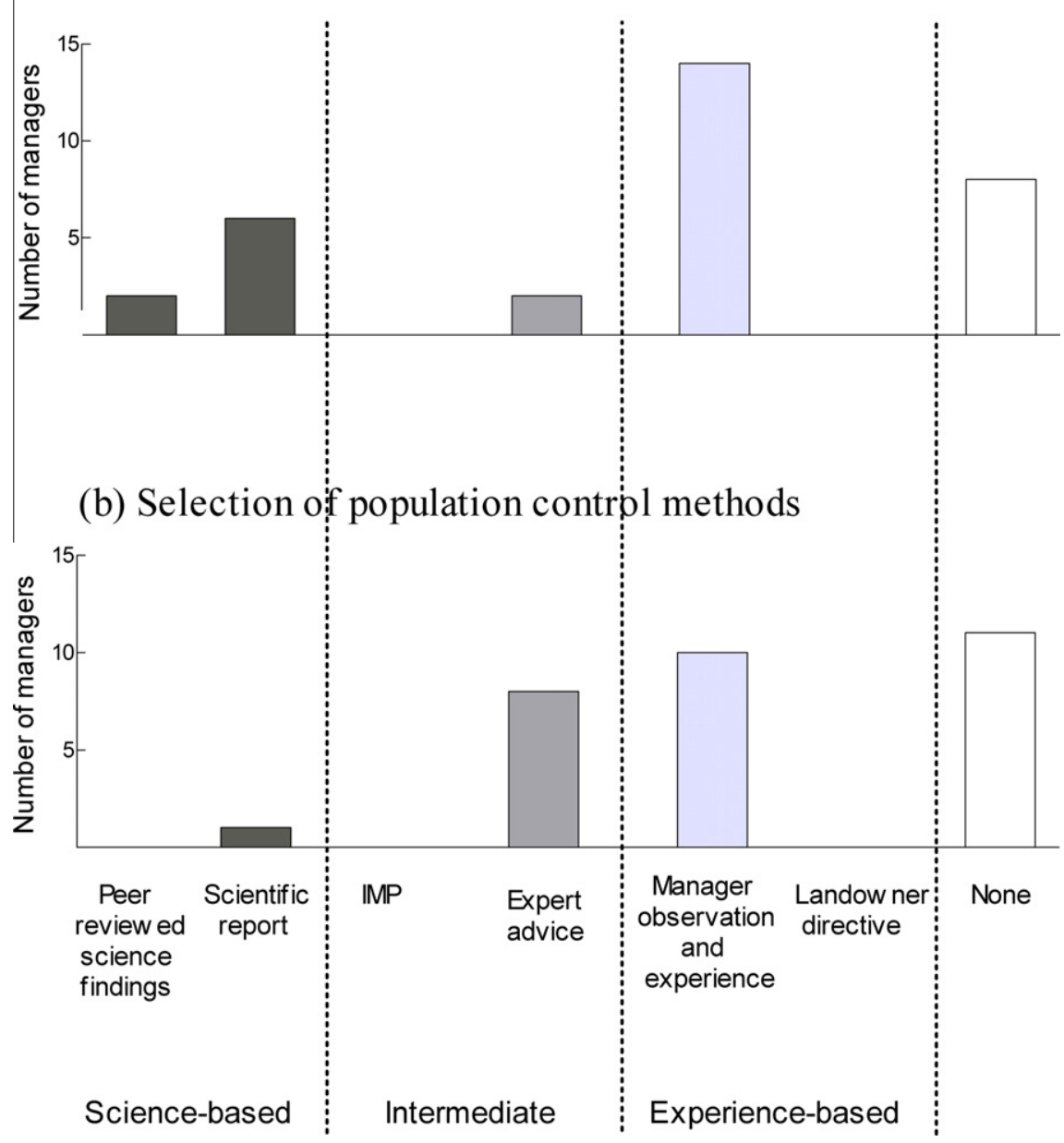

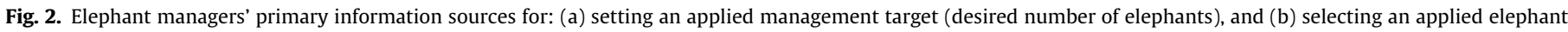
management method. $(N=30)$. Note IMP is Integrated Management Planning. 
Table 3

Summary of logistic regressions between explanatory factors and the probability of elephant managers' decisions being based on science-based information $(N=$ Number of managers), $P$ is probability calculated by $F$-test, $D^{2}$ is variation explained, ROC is Receiver Operator Characteristic, and cvROC is cross-validation ROC. Values in bold denote significant relationships. Note ROC and cvROC values are not provided for nonsignificant relationships.

\begin{tabular}{lllllll}
\hline Decision & Explanatory factor & $N$ & $P$ & $D^{2}$ & ROC & cvROC \\
\hline Objectives & & & & & & \\
& Size & $\mathbf{2 5}$ & $\mathbf{0 . 0 5}$ & $\mathbf{0 . 3 2}$ & $\mathbf{0 . 8 2}$ & $\mathbf{0 . 4 6}$ \\
& Tenure & $\mathbf{2 5}$ & $\mathbf{0 . 0 2}$ & $\mathbf{0 . 2 6}$ & $\mathbf{0 . 7 8}$ & $\mathbf{0 . 7 3}$ \\
& Manager experience & 25 & 0.64 & 0.085 & & \\
& Manager qualifications & 25 & 0.71 & 0.02 & & \\
& Planning timeframe & $\mathbf{2 5}$ & $\mathbf{0 . 0 0 4}$ & $\mathbf{0 . 3 7}$ & $\mathbf{0 . 8 7}$ & $\mathbf{0 . 6 0}$ \\
& & & & & & \\
Issues & 30 & 0.29 & 0.14 & & \\
& Size & 30 & 0.58 & 0.03 & & \\
& Tenure & 30 & 0.36 & 0.13 & & \\
& Manager experience & 30 & 0.37 & 0.06 & & \\
& Manager qualifications & $\mathbf{3 0}$ & $\mathbf{0 . 0 3}$ & $\mathbf{0 . 2 7}$ & $\mathbf{0 . 8 1}$ & $\mathbf{0 . 6 7}$ \\
& Planning timeframe & & & & & \\
Desired number of elephants & & & & \\
& Size & 26 & 0.44 & 0.13 & & \\
& Tenure & 26 & 0.38 & 0.07 & & \multirow{2}{*}{$\mathbf{0 . 9 7}$} \\
& Manager experience & $\mathbf{2 6}$ & $\mathbf{0 . 0 3}$ & $\mathbf{0 . 6 3}$ & $\mathbf{0 . 8 7}$ & \\
Manager qualifications & 26 & 0.75 & 0.03 & & \\
& Planning timeframe & $\mathbf{2 6}$ & $\mathbf{0 . 0 4}$ & $\mathbf{0 . 3 6}$ & $\mathbf{0 . 8 5}$ & $\mathbf{0 . 7 3}$ \\
\hline
\end{tabular}

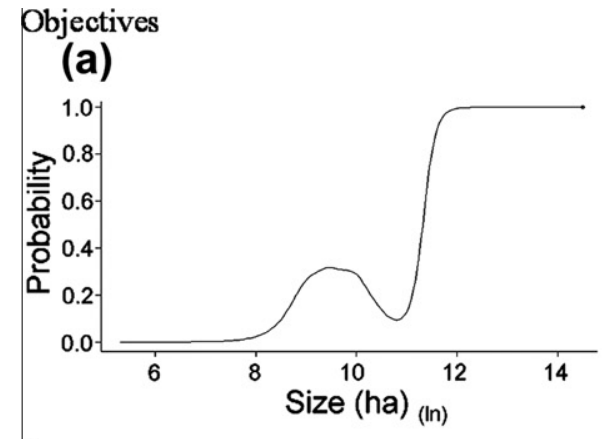

(b)

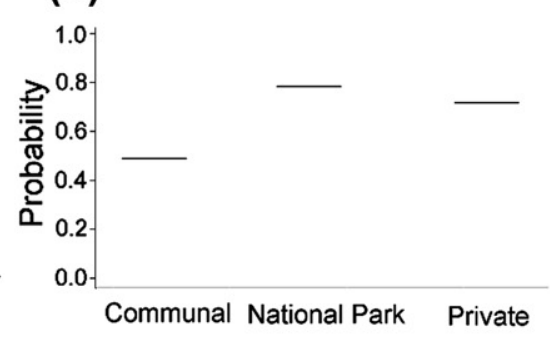

Issues

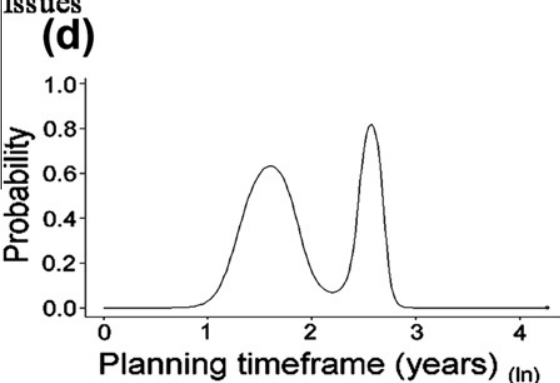

\section{Desired number of elephants}

(e)

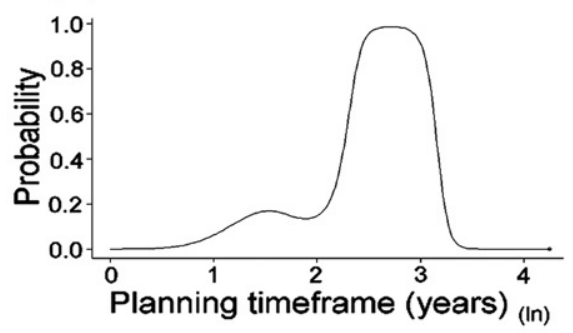

these regressions suggested high model accuracy (all $>0.75$ ) but except for tenure, performed poorly under cross validation (Table 3 ). Hence the relationships between the probability of a manager developing objectives based on science-based information and management area size and planning timeframe should be considered indicative only. Managers of large areas and of national parks were more likely to rely on science-based information to develop objectives (Fig. 4a and b). Managers with medium term planning timeframes (between 8 and 12 years) were less likely than those with shorter planning timeframes ( $<8$ years) or longer planning timeframes ( $>12$ years) to rely on science-based information to develop objectives (Fig. 4c).

Issues; Only planning timeframe significantly, but weakly $\left(D^{2}=0.27\right)$, predicted the probability of a manager identifying issues based on science-based information. This model was reasonably accurate $(\mathrm{ROC}=0.81)$ but performed poorly under cross validation ( $\mathrm{cvROC}=0.67$ ). Thus, the relationship should be considered indicative. Managers with planning timeframes between 3 and 7 years or between 18 and 19 years were more likely to identify issues according to science-based information (Fig. 4d).

Desired number of elephants; Planning timeframes and manager experience significantly predicted the probability of a manager determining a desired number of elephants according to sciencebased information. The relationship with planning timeframe was weak $\left(D^{2}=0.36\right)$ and although reasonably accurate $(\mathrm{ROC}=$ 
0.85 ) did not perform as well under cross validation $(\mathrm{cvCOR}=0.73$ ) (Table 3). The relationship between planning timeframe and probability of a manager basing his decision on science-based information is therefore indicative only. In contrast manager experience strongly explained the probability of a manager using sciencebased information $\left(D^{2}=0.63\right)$, and the model was highly accurate $(\mathrm{ROC}=0.97)$ and performed well under cross validation $($ cvROC $=0.87)$ (Table 3$)$. The probability of a manager using science-based information was lowest when managers' experience ranged between 7 and 20 years (Fig. 4f).

\subsection{Managers perspectives}

\subsubsection{Value of science findings for elephant management decisions}

All but one manager considered scientific information as important for making decisions regarding elephant management and the maintenance of biodiversity. The same 29 managers also considered such information as important when selecting management methods. Of these 29 managers, 27 actively sought out relevant science findings or were engaged, supporting or had commissioned scientific studies in their management area to assist with decision making. Of the three managers who were not actively seeking information from science, two explained that they were presently too busy, and the other explained that he did not see benefits in actively seeking out science findings or supporting site-specific scientific studies.

\subsubsection{Limitations}

Eight managers considered that there were no limitations to the incorporation of science into management decisions, however, the remaining 22 identified a variety of limitations. We grouped these into four categories: (1) Relevance; (2) Application; (3) Scientist credibility and attitudes; and (4) Organisational culture (Table 4). Note that several managers identified more than one limitation.

\subsubsection{Opportunities}

Six managers did not identify opportunities for better incorporation of scientific findings into management decisions. The remaining 24 identified a range of opportunities which we broadly grouped as: (1) Relevance; (2) Application, and (3) Communication

Table 4

Limitations identified by 30 elephant managers. Note that eight managers identified no limitations, and several managers identified more than one limitation.

\begin{tabular}{|c|c|}
\hline Limitation & $\begin{array}{l}\text { Number of } \\
\text { managers }\end{array}$ \\
\hline \multicolumn{2}{|l|}{ Relevance } \\
\hline Absence of site-specific scientific studies & 5 \\
\hline Science study timeframes are too long term & 4 \\
\hline Findings and recommendations made by scientists are impractical & 2 \\
\hline \multicolumn{2}{|l|}{ Application } \\
\hline $\begin{array}{l}\text { Financial and operational capacity to implement science based recommendations and support on-site scientific studies is lacking. This includes a } \\
\text { lack of available field staff to assist in field data collection and/or ensure the safety of scientists }\end{array}$ & 10 \\
\hline \multicolumn{2}{|l|}{ Scientist credibility and attitudes } \\
\hline Scientists are entrenched in their own agendas rendering findings subjective & 3 \\
\hline Scientists never have answers and cannot agree on best management options & 2 \\
\hline Too many scientific studies are done by young students with no experience in veldt management thus making findings unreliable & 1 \\
\hline Science findings become political making them difficult to incorporate into management decisions without controversy & 1 \\
\hline $\begin{array}{l}\text { Scientists are either arrogant and/or closed minded and do not listen to managers needs. These traits combined with a "we are telling you what you } \\
\text { need to know" approach results in a gap in understanding between scientists and managers and hence science findings and their practical } \\
\text { application }\end{array}$ & 4 \\
\hline $\begin{array}{l}\text { Scientists (in particular academia) consider small reserves and reserves with economic drivers as non-valuable study sites resulting in few studies } \\
\text { relevant to small management areas }\end{array}$ & 1 \\
\hline \multicolumn{2}{|l|}{ Organisational culture } \\
\hline $\begin{array}{l}\text { The workplace culture within some organisations does not promote reliance on science findings for management decision making. Specifically the } \\
\text { link between scientists and managers is vulnerable to personality differences. This stands in the way of effective translation of information from } \\
\text { science into management decisions }\end{array}$ & 2 \\
\hline No limitations & 8 \\
\hline
\end{tabular}

Table 5

Opportunities identified by 30 elephant managers. Note that six managers identified no opportunities, and several managers identified more than one opportunity.

\begin{tabular}{|c|c|}
\hline Opportunity & $\begin{array}{l}\text { Number of } \\
\text { managers }\end{array}$ \\
\hline \multicolumn{2}{|l|}{ Relevance } \\
\hline $\begin{array}{l}\text { Site-specific scientific studies would greatly improve the relevance of science findings for management decisions. Note that three managers } \\
\text { specifically sought their management areas to be promoted as a research destination, while two managers desired an on-site ecologist }\end{array}$ & 11 \\
\hline Scientific studies should be planned and reported according to different categories of management issues such as management area size & 2 \\
\hline \multicolumn{2}{|l|}{ Application } \\
\hline Scientists could share preliminary findings as studies progress to deliver answers to managers more quickly & 2 \\
\hline Scientists should be more practical and apply reality filters to study design and management recommendations & 3 \\
\hline \multicolumn{2}{|l|}{ Communication } \\
\hline Summarise science findings into management applications & 1 \\
\hline Create abstract filtering mechanism with keyword search functions to assist managers to rapidly access relevant information & 2 \\
\hline Scientists to assist managers to ask the right questions and managers to assist scientists to develop practical, relevant and useful studies & 4 \\
\hline Scientists to program a half day at each of their respective study sites to explain the relevance of their findings to managers & 1 \\
\hline Establish and/or maintain region specific management/science networks & 4 \\
\hline No opportunities & 6 \\
\hline
\end{tabular}


(Table 5). In addition to identified opportunities one manager felt that scientists need to appreciate, understand and incorporate the role of tourism and other economic drivers into their studies. Note that several managers identified more than one opportunity.

\section{Discussion}

Elephant managers in South Africa provided an opportunity to evaluate whether an applied science end-user group relied on information derived from research as a basis for strategic and applied management decisions. Our study revealed that while elephant managers value the contribution that science could make to management decisions for elephants, their reliance on science as an information platform for management decisions was low.

Of the 30 managers, all but one viewed science as an important basis for making decisions on elephant management and the maintenance of biodiversity. These managers also considered science important for selecting management methods. Indeed, all but three managers actively sought out relevant scientific findings or were engaged, supporting or had commissioned scientific studies in their management area. As an applied end-user group, elephant managers therefore demonstrated willingness to engage and be informed by science. In making decisions, however, at best only $30 \%$ of managers based the development of objectives, identification of issues, selection of management methods, identification of a desired number of elephants and selection of population control methods on science-based information. In contrast, most managers relied on experience-based information for these decisions.

The limited reliance on information derived from research for elephant management decisions is concerning. This is particularly because reliance on science-based information was lower for selection of methods than strategic decisions, suggesting that on-theground management decisions were being made in the absence of defendable scientifically based information (see Pullin et al., 2004; Pullin and Knight, 2005; Cook et al., 2010). Indeed only two managers based methods for mitigating elephant impacts on biodiversity management on science-based information and only one manager selected a population control method according to science-based information.

Although all elephant managers are explicitly directed by national policy to base their decisions on the best available science, our analyses of explanatory factors suggest some explanations for differences in the probability of managers basing decisions on science-based information. Our results weakly indicate that managers of large areas and managers of national parks were more likely to develop objectives according to information from science studies than managers of smaller reserves and ones in communal or private ownership. This may result from a greater proportion of studies being from larger study areas over longer timeframes and thus being more relevant to management decisions. Indeed, managers of larger areas and those publically owned, like national parks, may also have greater funding capacity and support by an on-site ecologist or even a team of scientists to assist with the implementation of science. Furthermore, because managing a larger area or publically owned land may be more complex than managing a small area, science-based information sources, in addition to practitioner experience, may be desirable when examining the outcomes of management decisions (see Cook et al., 2010). Planning timeframes also weakly explained variation in probability among managers to make decisions based on science. However, these models performed poorly under cross validation and the relationships were complicated and inconsistent among the three types of decisions. Hence the relationship between planning timeframe and the probability of managers basing their decisions on science was complex and to better understand how science-based information can contribute to short and long term strategic decisions the influence of planning timeframes warrants further investigation.

At the applied management level, our results strongly indicated that the years of manager experience predicted whether a manager determined a desired number of elephants for his management area according to science-based information. Of note managers with less than 8 years or more than 20 years experience were more likely to rely on science for these applied decisions. We can only speculate on reasons for this pattern. Perhaps as managers become more familiar with their subject matter they tend to rely increasingly on their own experience through observations and networks gained over time until a point of saturation is reached and further information is required.

Of particular note, manager qualifications did not contribute to the probability of a manager making strategic or applied decisions based on science. This was surprising because much of the course curricular of formal wildlife management, nature conservation, ecology and veterinary studies qualifications center about science-based information sources. We had therefore expected that managers with formal-academic qualifications would be more likely than their colleagues with no academic qualifications to base their decisions on science. Our study does not enable us to explain the lack of a relationship, however, its absence suggests that even among managers with formal exposure to science findings the "implementation gap" (Marris, 2007; see also Knight, 2009), between research and practical management exists.

The 'implementation gap' also known as "The Great Divide' (Possingham, 2009) is where theory ignores practice and practice ignores theory (Marris, 2007). Breaking down this gap is the biggest challenge for conservation biology (Armstrong and McCarthy, 2007). Together with the lack of a relationship between manager qualifications and science based decisions, the limitations identified by managers for the incorporation of science-based information into management decisions also appears to support the presence of the implementation gap for elephant management. Limitations primarily concerned the relevance and application of science and scientists attitudes. For instance, managers suggested that a lack of site-specific scientific studies, the length of time between studies beginning and findings of relevance being available to managers, and the limited practicality of science recommendations meant that they were forced to rely on non scientific studies. Managers also identified that a lack of funds to undertake or support scientific studies made it difficult to develop objectives, identify issues and select methods relevant to their management area.

In contrast to limitations identified by managers, those identified by conservation biologists for making differences to management decisions focus more widely on how they work and who they work with. In a self review of their performance, conservation biologists perceived that "conservation is primarily not about biology but about people and choices they make" such that "the key to increasing the future contribution of biologists to on-the-ground conservation interventions lies in accepting that reality, and in working much more closely with experts from other disciplines especially the social sciences" (Balmford and Cowling, 2006). Also, authors of applied ecology papers considered that the sheer geographical scale at which applied ecologists must often work limited end-user application (Ormerod et al., 2002). Furthermore, Flashpohler et al. (2000) noted that a neglect of issues by agencies, lack of funding, public opposition and lack of infrastructure were primary reasons for a low reliance on recommendations made by conservation biologists for management decisions.

Hence, in South Africa, the "implementation gap" between elephant managers and scientists may also be being fuelled by a lack of understanding by each party regarding the others needs and perceptions. This may not be surprising because most scientists are evaluated on the basis of their ability to produce refereed 
publications rather than the ability to recover species or restore ecosystems, while on the other hand managers are aware that most of what they do is unpublishable (Armstrong and McCarthy, 2007; also see Knight, 2009). Hence the measures for effectiveness of science and management outcomes differ (see Meffe, 2006; Armstrong and McCarthy, 2007; Zedler, 2007; Knight, 2009). Moreover, where wildlife agencies separate their science and management departments, or people from outside those agencies do not want to jeopardize future research opportunities by publishing management opinions, there may be reluctance by scientists to make management recommendations (Guldemond and van Aarde, 2008). For instance, of 218 publications which specifically evaluated the effects of elephant impacts on woody vegetation, $81 \%$ did not make any recommendations on managing elephant impact, even though $53 \%$ of them had concluded a negative effect on the measured variables (Guldemond and van Aarde, 2008).

Together with acknowledging the above limitations, the opportunities for increasing reliance on science-based information in management decisions may offer some practical and tangible solutions to closing the implementation gap in the management of elephants and possibly other species management. In particular, elephant managers suggested that site-specific scientific studies for their management areas would improve the relevance of science findings for making management decisions. Some managers also suggested that scientists design their studies and categorize their findings according to different management scenarios such as management area size. These suggestions are consistent with scientists own recognition that the greatest uptake their work was from studies conducted at the same geographical scale and complexity of the system to be managed (see Ormerod et al., 2002; Cook et al., 2010). Managers also suggested that further establishment of region specific management and science networks would provide a means for better communication between managers and scientists. Managers also sought to be more involved in study designs. These suggestions align with scientists' acknowledgements that managers often possess a deep and valuable working knowledge of the areas with which they are familiar, based on the results of practical experience and anecdotal observations of outcomes from management interventions (see Newton et al., 2007). Managers' suggestions of better access to information in the form of web-based resources and summaries of information/ recommendations also aligned with scientists' own observations that appropriate translations of their recommendations aimed at practitioners who may not be regular journal readers were more likely to convince practitioners of the value of science findings (Ormerod et al., 2002; Cook et al., 2010).

Managers also suggested that scientists share the results of their work in a more timely fashion with themselves and other colleagues. This finds accord with the notion that science findings would be more accessible and more effective within decision making processes if published manuscripts were not obliged to represent stand alone long term projects in their own right, but rather build on the findings of other studies to contribute to larger questions posed within robust theoretical frameworks (Armstrong and McCarthy, 2007).

Our study evaluated the information sources for decisions and perceptions held by elephant managers as a specific end-user group for scientific studies. Our sample size of 30 managers fairly represented this end-users group's perspectives. This is given the full range of management scenarios (management area size, elephant population size, fenced or not, years of management experience, management area tenure, etc.) over which we had manager participation. It is important to note however, that our study did not consider the views and perspectives of policy makers or ecologists working with any particular organization to which a management area belonged. A higher level of conceptual or strategic uptake of scientific findings into policy and planning documents among these groups may occur. Nor did it evaluate the uptake of science-based findings into other elephant management matters such as animal health and welfare where more direct uptake of technically directed science findings may occur.

Although it has been 30 years since conservation biology was launched to bridge the gap between theory, ecology and population biology on the one hand, and conservation policy and practice on the other (see Soule and Wilcox, 1980) the 'implementation gap' that remains, and that we identify here for elephant management, is not unique to conservation biology (Possingham, 2009). Indeed it is prevalent throughout almost all aspects of conservation management from species conservation management planning (Whitten et al., 2001) to systematic conservation planning for reserve network design (Knight et al., 2006). However, to the best of our knowledge, our study represents a first in terms of scientists identifying their own specific end-user group's perspectives of reasons for the gap (limitations) and opportunities for closing it. Our findings that elephant managers view science as highly valuable for decision making, and that there is broad alignment between managers and scientists own perspectives regarding opportunities for greater reliance or incorporation of science into management decisions, may augur well for closing the gap between theory and practice for the specific conservation management issue of elephants and biodiversity. Against this backdrop, we suggest that the practical opportunities identified by managers in this study including more site-specific scientific studies, categorization of findings according to different management scenarios, greater manager involvement in study designs, region specific management and science networks, access to information in the form of web-based resources and greater sharing of results among scientists, be implemented by scientists. These actions and resources could serve as avenues for scientists to contribute more effectively to reducing the decline of biodiversity by enabling elephant managers to more confidently and willingly base their strategic and applied decisions regarding elephants and biodiversity on information derived from scientific studies.

\section{Acknowledgements}

This study was funded through research grants from the International Fund for Animal Welfare and the University of Pretoria. We are indebted to the 30 elephant managers who willingly made their time available to participate in our interviews. Jake Overton and Jo Fourie assisted with the logistical planning and field work to conduct interviews. Sam Ferreira, Matt Grainger, Theresia Ott and D.G. Erasmas also assisted with fieldwork.

\section{References}

Armstrong, D.P., McCarthy, M.A., 2007. Big decisions and sparse data: adapting scientific publishing to the needs of practical conservation. Avian Conservation and Ecology 2, 14.

Balmford, A., Cowling, R.M., 2006. Fusion or failure? The future of conservation biology. Conservation Biology 20, 692-695.

Bekkby, T., Rinde, E., Erikstad, L., Bakkestuen, V., Longva, O., Christensen, O., Isæus, M., Isachsen, P.E., 2008. Spatial probability modelling of eelgrass (Zostera marina) distribution on the west coast of Norway. ICES Journal of Marine Science 65, 1093-1101.

Biggs, H., Slotow, R., Scholes, R.J., Carruthers, J., van Aarde, R., Kerley, G.H.I., Twine, W., Grobler, D.W., Berthshinger, H., Grant, C.C., Lötter, H.P.P., Blignaut, J., Hopkinson, L., Peel, M., 2008. Towards integrated decision making for elephant management. In: Scholes, R.J., Mennell, K.G. (Eds.), Elephant Management: A Scientific Assessment for South Africa. Wits University Press, Johannesburg, pp. 537-586.

Blignaut, J., de Wit, M., Barnes, J., 2008. The economic value of elephants. In: Scholes, R.J., Mennell, K.G. (Eds.), Elephant Management: A Scientific Assessment for South Africa. Wits University Press, Johannesburg, pp. 446-476.

Cook, C.N., Hockings, M., Carter (Bill), R.W., 2010. Conservation in the dark? The information used to support management decisions. Frontiers in Ecology and the Environment 8, 181-186. 
ARTICLE IN PRESS

10

K.D. Young, R.J. Van Aarde/Biological Conservation $x x x$ (2010) $x x x-x x x$

DEAT, 2008. National norms and standards for the management of elephants in South Africa. Department of Environmental Affairs and Tourism. Government Gazette, 8 May 2008.

Fielding, A.H., Bell, J.F., 1997. A review of methods for the assessment of prediction errors in conservation presence/absence models. Environmental Conservation $24,38-49$.

Flashpohler, D.J., Bub, B.R., Kaplin, B.A., 2000. Application of conservation biology research to management. Conservation Biology 14, 1898-1902.

Guldemond, R.A.R., van Aarde, R.J., 2008. A meta-analysis of the impact of african elephants on savanna vegetation. Journal of Wildlife Management 72, 892-899.

Kerley, G.I.H., Landman, M., Kruger, L., Owen-Smith, N., Balfour, D., de Boer, W.F., Gaylord, A., Balfour, D., de Boer, W.F., Lindsay, K., Slotow, R., 2008. Effects of elephants on ecosystems and biodiversity. In: Scholes, R.J., Mennell, K.G. (Eds.), Elephant Management: A Scientific Assessment for South Africa. Wits University Press, Johannesburg, pp. 146-205.

Knight, A.T., 2009. Is conservation biology ready to fail? Conservation Biology 23, 517.

Knight, A.T., Cowling, R.M., Campbell, B.M., 2006. An operational model for implementing conservation action. Conservation Biology 20,408-419.

Ladle, R.J., Gilson, L., 2009. The (imbalance of nature: a public perception time-lag? Public Understanding of Science 18, 229-242.

Maris, E., 2007. Conservation priorities: what to let go. Nature 450, 152-155.

Meffe, G.K., 2006. Conservation biology at twenty. Conservation Biology 20, 595 596.

Newton, A.C., Stewart, G.B., Diaz, A., Golicher, D., Pullin, A.S., 2007. Bayesian belief networks as a tool for evidence-based conservation management. Journal for Nature Conservation 15, 144-160.
Ormerod, S.J., Barlow, N.D., Marshall, E.J.P., Kerby, G., 2002. The uptake of applied ecology. Journal of Applied Ecology 39, 1-7.

Possingham, H., 2009. Dealing with 'The Great Divide' A tacit assumption or a universal truth? Decision Point 28, 2-3.

Pullin, A.S., Knight, T.M., 2005. Assessing conservation management's evidence base: a survey of management-plan compilers in the United Kingdom and Australia. Conservation Biology 19, 1989-1996.

Pullin, A.S., Knight, T.M., Stone, D.A., Charman, K., 2004. Do conservation managers use scientific evidence to support their decision-making? Biological Conservation 119, 245-252.

Boule, M.E., Wilcox, B.A., 1980. Conservation Biology: An Evolutionary-Ecological Approach. Sinauer Associates, Sunderland, Massachusetts.

van Aarde, R.J., Jackson, T.P., 2007. Megaparks for metapopulations: addressing the causes of locally high elephant numbers in southern Africa. Biological Conservation 134, 289-297.

van Aarde, R.J., Jackson, T.P., Ferreira, S.M., 2006. Conservation science and elephant management in southern Africa. South African Journal of Science 102, 385-388. van Aarde, R.J., Ferreira, S.M., Jackson, T.P., Page, B., de Beer, Y., Junker, J., Gough, K., Guldemond, R., Olivier, P.I., Ut, T., Thimble, M.J., 2008. Population biology and ecology. In: Scholes, R.J., Mennell, K.G. (Eds.), Elephant Management: A Scientific Assessment for South Africa. Wits University Press, Johannesburg, pp. 84-145.

Whitten, T., Holmes, D., MacKinnon, K., 2001. Conservation biology: a displacement behavior for academia? Conservation Biology 15, 1-3.

Zedler, J.B., 2007. Success: an unclear, subjective descriptor of restoration outcomes. Ecological Restoration 25, 162-168.

Please cite this article in press as: Young, K.D., Van Aarde, R.J. Science and elephant management decisions in South Africa. Biol. Conserve. (2010),

doi:10.1016/j.biocon.2010.11.023 